\title{
Methodology for Selecting the Best Model for Forecasts: The Case Study of Forest Bioenergy
}

\author{
Michael N. Tsatiris \\ Department of Forestry and Management of the Environment and Natural Resources, Democritus University of Thrace, Orestiada \\ 68200, Greece
}

\begin{abstract}
The aim of this paper is the analysis of methodology for selecting the best model for forecasting of fuelwood demand in Greece for the years 2020, 2025 and 2030 with a final objective the decision-making in the sector of forest bioenergy. A complete time series of historical data exists that concerns: (a) the consumption of fuelwood and (b) the six most important from the independent variables that could influence the consumption of fuelwood, whose data cover the time period 1989-2010. The evaluation and choice of the best model was realized with the help of the following six statistical criteria: (a) the size of standard error of theoretical values of dependant variable, S. E.; (b) the value of adjusted R square $\left(\mathrm{R}^{2}\right)$; (c) the non-existence of autocorrelation among the residuals (ei) through the criterion Durbin-Watson; (d) the statistical significance of models coefficients through $t$ criterion; (e) the statistical significance of models through F criterion and (f) the non-existence of multicolinearity through the values of Variance Inflation Factor.
\end{abstract}

Key words: Evaluation of models, choice of the best model, statistical criteria.

\section{Introduction}

The time series (data) that they concern in consumption of fuelwood and they are used in this research have been taken by the statements of the Ministry of Agriculture of Greece [1], they concern in the time period 1989-2010 (Table 1). The time series (data) of the independent variables (population of Greece, per capita income of a Greek, consumer price index , price of fuelwood, price of charcoal and price of heating oil) have been taken by the Yearbooks of National Statistical Authority of Greece [2] (Table 2). A complete time series of historical data exists that concerns: (a) the consumption of fuelwood and (b) the six independent variables, which cover the time period 1989-2010.

2. Models of Fuelwood Consumption: The Theory and Building

The authors used a linear multivariate model of

Corresponding author: Michael. N. Tsatiris, assistant professor, Ph.D., main research fields: biomass and bioenergy. E-mail: tsatiris@fmenr.duth.gr.
Table 1 Time series (data) of fuelwood consumption in the period 1989-2010.

\begin{tabular}{ll}
\hline Year & Consumption of fuelwood (in tons) \\
\hline 1989 & $2,479,841$ \\
1990 & $2,453,231$ \\
1991 & $2,434,326$ \\
1992 & $2,395,678$ \\
1993 & $2,378,456$ \\
1994 & $2,339,892$ \\
1995 & $2,312,956$ \\
1996 & $2,298,743$ \\
1997 & $2,275,654$ \\
1998 & $2,256,789$ \\
1999 & $2,231,213$ \\
2000 & $2,215,579$ \\
2001 & $2,209,620$ \\
2002 & $2,201,025$ \\
2003 & $2,189,027$ \\
2004 & $2,225,933$ \\
2005 & $2,278,091$ \\
2006 & $2,292,887$ \\
2007 & $2,343,035$ \\
2008 & $2,361,561$ \\
2009 & $2,379,430$ \\
2010 & $2,395,564$ \\
\hline
\end{tabular}


Table 2 Data of independent variables for the time period 1989-2010.

\begin{tabular}{|c|c|c|c|c|c|c|}
\hline Year & $\begin{array}{l}\text { Population of } \\
\text { Greece } \\
\text { (PG) }\end{array}$ & $\begin{array}{l}\text { Per capita income of } \\
\text { a Greek (euros in } \\
\text { current values, PCIG) }\end{array}$ & $\begin{array}{l}\text { Consumer price } \\
\text { index }(\mathrm{CPI})(\text { year as a } \\
\text { base: } 2002=100.0)\end{array}$ & $\begin{array}{l}\text { Price of fuelwood } \\
(\mathrm{PF}) \text { euros/ton }\end{array}$ & $\begin{array}{l}\text { Price of charcoal } \\
\text { (PCh) euros/ton }\end{array}$ & $\begin{array}{l}\text { Price of heating } \\
\text { oil (PO) } \\
\text { euros/1000 lt }\end{array}$ \\
\hline 1989 & $10,154,338$ & 9,532 & 78.4 & 115 & 795 & 410 \\
\hline 1990 & $10,206,352$ & 9,895 & 79.8 & 118 & 825 & 440 \\
\hline 1991 & $10,258,364$ & 10,258 & 80.1 & 120 & 850 & 480 \\
\hline 1992 & $10,325,937$ & 10,849 & 81.6 & 120 & 890 & 500 \\
\hline 1993 & $10,393,510$ & 11,028 & 82.3 & 122 & 905 & 560 \\
\hline 1994 & $10,461,083$ & 11,279 & 82.5 & 125 & 920 & 600 \\
\hline 1995 & $10,528,655$ & 11,346 & 84.8 & 130 & 935 & 650 \\
\hline 1996 & $10,596,228$ & 11,658 & 86.3 & 130 & 950 & 680 \\
\hline 1997 & $10,663,801$ & 11,763 & 88.3 & 135 & 960 & 720 \\
\hline 1998 & $10,731,374$ & 11,954 & 92.7 & 135 & 967 & 760 \\
\hline 1999 & $10,798,947$ & 12,103 & 94.3 & 138 & 972 & 790 \\
\hline 2000 & $10,866,521$ & 12,212 & 94.6 & 140 & 975 & 840 \\
\hline 2001 & $10,934,097$ & 12,275 & 96.8 & 140 & 975 & 880 \\
\hline 2002 & $10,922,209$ & 12,321 & 100.0 & 142 & 980 & 910 \\
\hline 2003 & $10,910,318$ & 12,392 & 113.7 & 143 & 987 & 960 \\
\hline 2004 & $10,898,428$ & 12,151 & 136.9 & 144 & 990 & 1,000 \\
\hline 2005 & $10,886,541$ & 11,943 & 163.6 & 144 & 995 & 1,050 \\
\hline 2006 & $10,874,653$ & 11,712 & 189.5 & 145 & 1,000 & 1,090 \\
\hline 2007 & $10,862,759$ & 11,648 & 216.8 & 146 & 1,005 & 1,120 \\
\hline 2008 & $10,850,867$ & 11,383 & 240.5 & 148 & 1,012 & 1,170 \\
\hline 2009 & $10,838,973$ & 11,125 & 262.8 & 150 & 1,017 & 1,210 \\
\hline 2010 & $10,815,197$ & 10,878 & 285.2 & 152 & 1,022 & 1,270 \\
\hline
\end{tabular}

regression (linear multiple regression model) (Eq. (1)) with the general form [3-5]:

$$
Y_{i}=\beta_{0}+\beta_{1} X_{i 1}+\beta_{2} X_{i 2}+\ldots+\beta_{k} X_{i k}+\varepsilon_{i}
$$

Where, $\mathrm{Y}_{\mathrm{i}}$ : the dependant variable;

$\mathrm{X}_{\mathrm{i} 1}, \mathrm{X}_{\mathrm{i} 2}, \ldots, \mathrm{X}_{\mathrm{i \kappa}}$ : the independent variables;

$\beta_{0}, \beta_{1}, \ldots, \beta_{\mathrm{\kappa}}$ : the (unknown parameters) coefficients of regression;

$\varepsilon_{\mathrm{i}}$ : the error or term of error or disorderly term.

The error $\varepsilon_{i}$ contains each deviation of model from the real situation. Thus, apart from the likely errors of measurements, it also contains errors of adaptation that they due either to omission of variables or to use of variables that they are not related to the dependant variable $[6,7]$.

The dependant variable which is studied here is the annual consumption of fuelwood in tons.

The assumptions that the authors make here in the multiple linear regression are the followings [8]: (a) The variances of distributions of the random dependant variable $\mathrm{Y}_{\mathrm{i}}$ are all equal each other and they are equal to $\sigma^{2}$;

(b) The values of dependant variable $Y_{i}$ are all independent each other;

(c) The values of $\mathrm{k}$ independent variables are known constant, where they could be measured without some error. This means that the authors are reported to a model of regression where the independent variables $\mathrm{X}_{\mathrm{i}}$ are not random;

(d) In each total of values of independent variables $\mathrm{X}_{\mathrm{i}}$ corresponds a distribution of the random variable $\mathrm{Y}_{\mathrm{i}}$. The distributions of the dependant variable $\mathrm{Y}_{\mathrm{i}}$ it is supposed that they follow the normal distribution.

A model (equation) in order to be more reliable it should include the most and mainly the most important from the independent variables $X_{i 1}$, $\mathrm{X}_{\mathrm{i} 2}, \ldots, \mathrm{X}_{\mathrm{i}}$ which influence the dependant variable $\mathrm{Y}_{\mathrm{i}}$. In other words, at the process of search of the best 
relatively equation (model), the independent variables (factors) which actually practice a significant impact on the dependant variable $Y_{i}$ should be not omitted by the equation. Moreover, it is required the variables to be quantitative, that is to say they should describe measurable sizes [9]. The independent variables it is able in this case to be: the population of Greece (PG), the per capita income of a Greek (PCIG), the consumer price index (CPI), the price of fuelwood $(\mathrm{PF})$, the price of charcoal $(\mathrm{PCh})$ and the price of heating oil (PO).

The larger the sample of observations the more accurate will be the estimate of the equation, but provided that a complete time series of data exists. Events which would have as a consequence the disturbance of interaction of the correlated to the equation variables did not take place at the corresponding time period of sample [7]. The time period 1989-2010 can be characterized as a period relatively normal, without significant disturbances and consequently the probability for change of equation structure is low.

The authors gathered data from all the factors (independent variables) which it is supposed that they practice a more or less significant influence on the consumption of fuelwood. Thus, the authors collected data for the time period 1989-2010 for six factors, as the population of Greece (PG), the per capita income of a Greek (PCIG), the consumer price index (CPI), the price of fuelwood (PF), the price of charcoal (PCh) and the price of heating oil (PO) (Table 2).

The authors suppose for the error or disorderly term $\varepsilon_{\mathrm{i}}$ that $[6,7,10-12]$ :

(a) It is a random variable (it takes positive and negative values and it follows normal distribution);

(b) It has a mean equal to zero, $\mu=0$ and a constant variance $\sigma^{2}$, that is to say $\varepsilon_{\mathrm{i}} \sim \mathrm{N}\left(0, \sigma^{2}\right)$;

(c) The values $\varepsilon_{\mathrm{i}}$ and $\varepsilon_{\mathrm{j}}$ for $\mathrm{i}, \mathrm{j}$ are uncorrelated, that is to say $\operatorname{cov}\left(\varepsilon_{\mathrm{i}}, \varepsilon_{\mathrm{j}}\right)=0, \mathrm{i}, \mathrm{j}$;

(d) The residuals $\varepsilon_{\mathrm{i}}$ are independent each other.

The following two suppositions are additionally required for the estimate of the preceding linear multivariate model [11]:

(a) The number of observations of sample is higher than the number of coefficients of model that the authors want to estimate, namely that $\mathrm{n}>\mathrm{k}+1$ (22> 7). This supposition ensures the essential degrees of freedom for the estimate as well as for the control of model;

(b) Among the independent (interpretative) variables do not exist accurate linear relations, that is to say multicollinearity does not exist.

The estimate of regression coefficients became with the help of subprogram Stepwise Regression of SPSS for Windows [13, 14]. All the possible variables $\mathrm{k}$ were imported which it was judged that they could influence the dependant variable as well as all the possible combinations of them $\left(2^{\mathrm{k}}-1\right)$.

The choice of interpretative variables for the building of models became progressively with the method of Stepwise Regression which is based on the maximization of $\left(\mathrm{R}^{2}\right)$ adjusted $\mathrm{R}$ Square. This method combines the choice of interpretative variables with the technique of their addition in the regression as well as with the technique of omission of variables that they previously had been imported [7, 9].

\section{Models of Fuelwood Consumption: The Output}

\subsection{Models of Fuelwood}

In the stepwise multiple regression, initially the authors registered the per capita income which is responsible for the $77.4 \%$ of variance on the consumption of fuelwood $\left(\mathrm{F}_{1,20}=113.786, \mathrm{p}<0.001\right)$ (Table 3). Afterwards, the price of fuelwood was added and it is responsible for an additional 3.9\% of variance on the consumption of fuelwood $\left(\mathrm{F}_{1,19}=\right.$ $41.514, p=0.012)$ (Table 3). Afterwards, the price of heating oil was added and it is responsible for an additional $0.9 \%$ of variance on the consumption of fuelwood $\left(\mathrm{F}_{3,18}=27.852, \mathrm{p}=0.016\right)($ Table 3$)$. 
The model 3 was selected which has the highest value of Adjusted $\mathrm{R}$ Square $\left(\mathrm{R}^{2}\right)$, equal to 0.818 (Table 3). The predictors per capita income, price of fuelwood and price of heating oil influence significantly the dependent variable consumption of fuelwood (Table 3). The values of the column "Sig. F Change" show that the improvement of adaptation for the three models is significant (Table 3). The t values $\left(t_{1}, t_{2}\right.$ and $\left.t_{3}\right)$ show that the three independent variables contribute significantly to the prediction (Table 4).

The best model of fuelwood consumption is the model 3 which is expressed as in Eq. (2) (Table 4):

$$
\begin{gathered}
C_{f}=2,485,497.561-0.672 P C I G \\
-0.215 P F+1.887 P O \\
\mathrm{R}^{2}=0.818 \text { S. E. }=9.681 \text { D. W. }=1.93 \\
\mathrm{t}_{1}=8.096>\mathrm{t}_{0.05,18}=1.734 ; \\
\mathrm{t}_{2}=8.958>\mathrm{t}_{0.05,18}=1.734 ; \\
\mathrm{t}_{3}=12.096>\mathrm{t}_{0.05,18}=1.734 ;
\end{gathered}
$$

Table 3 Model summary

\begin{tabular}{llllllllll}
\hline \multirow{2}{*}{ Model } & $\mathrm{R}$ & R square & $\begin{array}{l}\text { Adjusted } \\
\text { R square }\end{array}$ & $\begin{array}{l}\text { Std. error of } \\
\text { the estimate }\end{array}$ & $\begin{array}{l}\text { R square } \\
\text { change }\end{array}$ & F change & df1 & df2 & Sig. F change \\
\hline 1 & $0.880 \mathrm{a}$ & 0.774 & 0.770 & 25.232 & 0.774 & 113.786 & 1 & 20 & 0.000 \\
2 & $0.902 \mathrm{~b}$ & 0.813 & 0.804 & 13.324 & 0.039 & 41.514 & 1 & 19 & 0.012 \\
3 & $0.907 \mathrm{c}$ & 0.822 & 0.818 & 9.681 & 0.009 & 27.852 & 2 & 17 & 0.016 \\
\hline
\end{tabular}

*a. Predictors: (constant), per capita income;

b. Predictors: (constant), per capita income, price of fuelwood;

c. Predictors: (constant), per capita income, price of fuelwood, price of heating oil.

Table 4 Regression coefficients.

\begin{tabular}{llllll}
\hline \multirow{2}{*}{ Model } & \multicolumn{2}{l}{ Unstandardized coefficients } & \multicolumn{2}{l}{$\begin{array}{l}\text { Standardized } \\
\text { coefficients }\end{array}$} \\
\cline { 2 - 6 } & $\mathrm{B}$ & Std. error & Beta & $\mathrm{t}$ & Sig. \\
\hline 1 (Constant) & $2,503,224.136$ & 145.338 & & $17,223.466$ & 0.634 \\
Per capita income & -0.412 & 0.132 & 0.880 & 3.121 & 0.000 \\
2 (Constant) & $2,497,586.423$ & 103.514 & & $24,128.006$ & 0.523 \\
Per capita income & -0.524 & 0.198 & 0.687 & 2.646 & 0.000 \\
Price of fuelwood & -0.138 & 0.049 & 0.262 & 2.816 & 0.012 \\
3 (Constant) & $2,485,497.561$ & 78.327 & & $31,732.321$ & 0.474 \\
Per capita income & -0.672 & 0.083 & 0.626 & 8.096 & 0.000 \\
Price of fuelwood & -0.215 & 0.024 & 0.214 & 8.958 & 0.012 \\
Price of heating oil & 1.887 & 0.156 & 0.127 & 12.096 & 0.016 \\
\hline
\end{tabular}

\footnotetext{
* Dependent variable: consumption of fuelwood.
}

$\mathrm{F}=27.852>\mathrm{F}_{0.05,3,18}=3.16$;

$\mathrm{VIF}_{(\mathrm{PCIG}, \mathrm{PF})}=3.352$;

$\mathrm{VIF}_{(\mathrm{PCIG}, \mathrm{PO})}=2.136$;

$\mathrm{VIF}_{(\mathrm{PF}, \mathrm{PO})}=2.748$.

Where, the values in the parentheses depict the standard errors of constant and the coefficients (bi) of independent variables of the model:

$\mathrm{R}^{2}$ : The value of Adjusted R Square;

S. E.: The standard error of theoretical values of dependant variable;

D. W.: The Durbin-Watson test;

VIF: The values of Variance Inflation Factor for the various pairs of independent variables of a selected model by which the existence of multicolinearity is tested;

The authors define level of significance $\alpha=0.05$. The authors realize unilateral control;

$\mathrm{C}_{\mathrm{f}}$ : The variable that declares the consumption of fuelwood (dependent variable); 
PCIG: The variable that declares the per capita income of a Greek (predictor, independent variable);

PF: The variable that declares the price of fuelwood (predictor, independent variable);

PO: The variable that declares the price of heating oil (predictor, independent variable).

\subsection{Evaluation of Models}

\subsubsection{Control of Models}

After the completion of models building (Tables 3 and 4 ), the best model was selected according to the following statistical criteria-controls:

- The size of standard error of theoretical values of dependant variable, S. E.;

- The value of adjusted $\mathrm{R}$ square, $\mathrm{R}^{2}$;

- The non-existence of autocorrelation among the residuals (ci) through the criterion Durbin-Watson;

- The statistical significance of models coefficients through t criterion;

- The statistical significance of models through F criterion;

- The non-existence of multicolinearity through the values of Variance Inflation Factor (VIF).

3.2.2 The Standard Error of Theoretical Values of Dependant Variable, S. E.

The standard error of theoretical values of dependant variable (S. E.) was used as one of the more basic criteria for the choice of each model. The lower the value of this standard error is the closer to the estimated line of model are found the real values of dependant variable in the population, that is to say the value of dependant variable for given values of independent variables is so much more accurate and consequently the model is so much better $[6,8]$.

The standard error (S. E.) of theoretical values of dependant variable for the model 3 is the lowest one than that of the other models and it comes to 9.681 (Table 3).

3.2.3 The Value of Adjusted R Square, $\mathrm{R}^{2}$

The adjusted $R$ square $\left(R^{2}\right)$ is considered as a better indicator of a model adaptation than the $\mathrm{R}$ square $\left(\mathrm{R}^{2}\right)$ if the size of sample and the number of independent variables differ. The adjusted $\mathrm{R}$ square $\left(\mathrm{R}^{2}\right)$ receives values between 0 and 1 , but it can receive even negative value $[7,10,12,15,16]$. In this paper, the size of sample $(n=22$, number of past years 1989-2010) and the number of independent variables (6) differ. On the basis of this criterion, it was selected the model 3 which has the highest value of Adjusted R Square $\left(\mathrm{R}^{2}\right)$ that runs to 0.818 (Table 3) and this means that model 3 interprets the $81.8 \%$ of scattering, that is to say it is adapted enough satisfactorily on the data.

\subsubsection{Control of Autocorrelation}

If the sequential errors of the estimate of a model are related, the authors say that autocorrelation of residuals or disorderly terms exist. The autocorrelation in the errors of the estimate is in general indication of a bad specialization of a model. For this control is used the criterion Durbin-Watson [5, 7]. If the value D. $\mathrm{W}$. is close to the number 2 , then the authors are sure that autocorrelation does not exist. If it is close to zero then the existence of autocorrelation is sure [17-19]. In different cases, the authors are compelled to resort to marginal values given from statistical tables and after comparison proportionally to decide [10]. In the case of model 3, the value D.W is equal to 1.93 and so the authors are sure that autocorrelation does not exist. This constitutes indication of a good specialization of the model.

3.2.5 Control of the Statistical Significance of Models Coefficients through T-criterion

This control becomes with the $t$-criterion with which is checked each coefficient $\left(b_{i}\right)$ of the model, separately, if it is statistically significantly different from zero in level of significance $\alpha=0.05$. This control concerns the statistical significance of each independent variable separately on the interpretation of changes of the dependant variable. Rejection of null hypothesis $\left(\mathrm{H}_{0}\right)$ means that the independent variable that the authors examine is statistically significant for the interpretation of the dependant variable, that is to 
say it influences the dependant variable, namely linear relation exists between the $\mathrm{Y}$ and $\mathrm{X}[20,21]$.

In the selected model 3, the values of $t$ for each independent variable are higher than the corresponding critical value of $t_{\alpha, v}$ the given from the statistical tables in level of significance $\alpha=5 \%$ and for $v$ degrees of freedom. Consequently, in level of significance $5 \%$, the null hypothesis $\left(\mathrm{H}_{0}\right)$ is rejected and this means that the independent variable that the authors examine each time is statistically significant for the interpretation of dependant variable, that is to say it influences the dependant variable, namely linear relation between each particular independent variable and dependant variable exists. From the preceding, it results that for the selected model 3 each one from the independent variables influences the dependant variable and at the same time that the coefficients $\left(b_{i}\right)$ are significantly different from zero.

3.2.6 Control of the Statistical Significance of Models through F-criterion

By F-criterion the authors check the statistical significance of all together of the independent variables in the interpretation of changes of the dependant variable. The value of $F$ for each model is checked if the particular relation between the dependant and the independent variables of model really exists [21]. Rejection of null hypothesis means that at least one of the independent variables is statistically significant for the interpretation of dependant variable, that is to say that at least one of the independent variables influences the dependant variable [21-23]. However, the model in order to be satisfactory, beyond the rejection of the null hypothesis $\left(\mathrm{H}_{0}\right)$, it should be in force $\mathrm{F}>4 \mathrm{~F}_{\mathrm{a}, \mathrm{v1}, v 2}$ [3]. For the application of two preceding criteria it is supposed that the distribution of errors is normal with medium value zero and variance $\sigma^{2}$, that is to say that $\varepsilon_{\mathrm{i}} \sim \mathrm{N}\left(0, \sigma^{2}\right)[11]$.

In the selected model 3 , the value $\mathrm{F}$ is higher than the corresponding critical value $F_{\alpha, v 1, v 2}$ given from the statistical tables in level of significance $\alpha=5 \%$ and for $v_{1}$ and $v_{2}$ degrees of freedom. Consequently, in level of significance $5 \%$, the null hypothesis $\left(\mathrm{H}_{0}\right)$ is rejected, but likewise for the selected model 3 be in force $\mathrm{F}>4 \mathrm{~F}_{\alpha, v 1, v 2}$ thing that means that this model is satisfactory.

\subsubsection{Control of Multicolinearity}

The values of Variance Inflation Factor (VIF) for the various pairs of independent variables of the selected model 3 are relatively low, thing that means that accurate linear relations among the independent variables do not exist, that is to say multicolinearity does not exist, but even if it exists, this is not harmful. Norusis [13] states that multicolinearity can be harmful if the VIF values are higher than 10.

\section{Conclusion}

The selected model 3 (Table 4) of fuelwood consumption is the best model (Eq. (2)) because it has the highest value of Adjusted $\mathrm{R}$ Square, thing that means that this model interprets a high percentage $(81.8 \%)$ of deviations of theoretical from the real values, that is to say it is adapted enough satisfactorily on the data. The signs of independent variables are in conformity with the economic theory. The per capita income of a Greek influences negatively the consumption of fuelwood because fuelwood constitutes a product of cheapness. Concretely, as the per capita income increases, the standard of living rises and therefore the consumption of fuelwood decreases, with turn to mining fuels. The price of fuelwood influences negatively the consumption of fuelwood, namely as the price of fuelwood increases the consumption of fuelwood decreases. The price of heating oil influences positively the consumption of fuelwood, namely as the price of heating oil increases the consumption of fuelwood increases.

In the selected model 3, the standard errors of coefficients (bi) are lower than the half of coefficients (bi). The standard error (S. E.) of theoretical values of dependant variable for the model 3 is the lowest one than that of the other models and it comes to 9.681 . 
The Durbin-Watson test (D. W.) shows that autocorrelation among the residuals or disorderly terms $\varepsilon_{\mathrm{i}}$ does not exist. The values of Variance Inflation Factor (VIF) for the various pairs of independent variables of the selected model 3 are lower than 4 , thing that means that multicolinearity does not exist.

In the selected model 3 , the values of $\mathrm{t}$ for each independent variable are higher than the corresponding critical value of $t_{\alpha, v}$ given from the statistical tables in level of significance $\alpha=5 \%$ and for $v$ degrees of freedom and this means that each one from the three independent variables is statistically significant for the interpretation of dependant variable, that is to say it influences the dependant variable.

In the selected model 3, the value $\mathrm{F}$ is higher than the corresponding critical value $F_{\alpha, v 1, v 2}$ given from the statistical tables in level of significance $\alpha=5 \%$ and for $v_{1}$ and $v_{2}$ degrees of freedom and besides $F>4 F_{\alpha}$, $v 1, v 2$ be in force, thing that means that this model is satisfactory. After the relative controls it was ascertained that the basic assumptions are not violated by the selected model, thing that means that this model has a foreseeable ability. The selected model was used for the forecast of fuelwood consumption for the years 2020, 2025 and 2030. The reliability of these forecasts depends on the usable model. This paper could constitute a guide for those who would like to deal with the building of models for forecasts, because this paper provides a concentrated terminology for the building's conditions, the control and evaluation of the selected model.

\section{Acknowledgments}

The author would like to thank the reviewers of this paper for their valuable comments and contribution to the improvement of the manuscript.

\section{References}

[1] Ministry of Agriculture of Greece. 2012. Year-Book of Statistical Data. Athens: Directorate of Forests Planning.
[2] National Statistical Authority of Greece. 2012. "Year-Books of Statistical Data." Statistical Survey 7 (3): 146-232.

[3] Draper, N., and Smith, H. 1981. Applied Regression Analysis Second Edition. New York: John Wiley and Sons.

[4] Panaretos, J. 1994. Linear Models. Athens: Economic University Publications.

[5] Tsatiris, M. 2001. "Forecasting of Supply and Demand of Forest Biomass for Energy Production." Doctoral Dissertation, The Aristotelian University.

[6] Hristou, G. 1982. Introduction to Econometrics. Thessaloniki: Aristotle University Publications.

[7] Haratsis, E. 1992. Econometric Methods and Applications. Athens: National University Publications.

[8] Katos, A. 1984. Statistics. Thessaloniki: The Observer Press Co..

[9] Bora-Senta, E., and Moysiadis, H. 1997. Applied Statistics Multiple Regression Time Series. Thessaloniki: The Ziti Press Co..

[10] Kintis, A. 1982. Econometrics Volume A. Athens: The Gutenberg Press Co..

[11] Manos, V. 1997. Agricultural Economic Statistics. Thessaloniki: The Ziti Press Co..

[12] Lazaridis, A. 1998. Econometrics I. Thessaloniki: Aristotle University Publications.

[13] Norusis, M. 2008. SPSS 16.0 Guide to Data Analysis. New Jersey: Prentice Hall.

[14] SPSS Inc. 2007. SPSS 16.0 Brief Guide. Chicago: SPSS Inc Publisher.

[15] Juselius, K. 1999. "Models and Relations in Economics and Econometrics." Journal of Economic Methodology 6 (2): 259-290.

[16] Geweke, J. 2010. Complete and Incomplete Econometric Models. Princeton and Oxford: Princeton University Press.

[17] Goldberger, A. 1964. Econometric Theory. New York: John Wiley and Sons.

[18] Kmenta, J. 1971. Elements of Econometrics. New York: The MacMillan Publishing Company.

[19] Gujarati, D. 1999. Essentials of Econometrics Third Edition. Boston: McGraw-Hill Irwin.

[20] Psoinos, D. 1999. Statistics. Thessaloniki: The Ziti Press Co..

[21] Halkos, G. 2000. Statistics. Athens: The Typothito Press Co..

[22] Papadimitriou, G. 1985. Statistics. Thessaloniki: Aristotle University Publications.

[23] Heckman, J., and Leamer, E. 2001. Handbook of Econometrics. Amsterdam, Netherlands: Elsevier Science B.V.. 